\title{
Consumo e digestibilidade aparente de alguns componentes nutritivos da silagem de sorgo (Sorghum bicolor L. Moench) com ou sem aditivos, em ovinos ${ }^{1}$
}

\author{
Intake and digestibility of some nutritional components of sorghum \\ silage (Sorghum bicolor L. Moench) with or without additives in sheep
}

\author{
Rômulo Alexandre Correa ${ }^{2}$; Leandro das Dores Ferreira da Silva ${ }^{3 *}$; \\ Vanderlei Bett ${ }^{3}$; Valdecir de Souza Castro5; Edson Luis de Azambuja Ribeiro ${ }^{3}$; \\ Fernando Henrique Brussi Beran²; Marco Antônio da Rocha ${ }^{3}$; \\ Jane Maria Bertocco Ezequiel ${ }^{4}$; Fernando Luiz Massaro Júnior ${ }^{5}$
}

\section{Resumo}

\begin{abstract}
Este trabalho teve como objetivos avaliar o consumo médio diário da silagem de sorgo, da silagem de sorgo aditivada com fubá e da silagem de sorgo aditivada com Lacto Silo., bem como estimar a digestibilidade aparente in vivo e pelo uso da lignina em detergente ácido (LDA) como indicador, e correlacionar os valores das digestibilidades aparentes de alguns componentes nutritivos destas três silagens. Foram utilizados nove ovinos machos, castrados, sem raça definida, com peso médio inicial de $30,7 \mathrm{Kg}$, distribuídos em três tratamentos e dois períodos, alojados em gaiolas metabólicas. A silagem de sorgo sem aditivos proporcionou maiores níveis de consumo de matéria seca (MS), matéria orgânica (MO), fibra em detergente ácido (FDA), fibra em detergente neutro (FDN), carboidratos totais (CT) e hemicelulose (HEM). Os coeficientes de digestibilidade aparente dos componentes nutritivos das três silagens foram semelhantes quando avaliados pela coleta total de fezes. Já utilizando a LDA como indicador houve diferença significativa apenas para a FDA, onde a silagem de sorgo sem aditivos foi superior a silagem de sorgo aditivada com Lacto Silo. A silagem de sorgo com fubá foi semelhante às duas. Houve correlação significativa apenas para CT e HEM entre as duas metodologias usadas para estimar as digestibilidades.
\end{abstract}

Palavras chave: Correlação, fubá, indicador.Inoculante, lignina

\begin{abstract}
This trial was conducted to evaluate the average daily intake of sorghum silage, sorghum silage with corn meal as additive and sorghum silage with Lacto Silo as additive. It was also evaluated the apparent digestibility in vivo and using the acid detergent lignin (ADL) as marker. Values of apparent digestibility of some nutritive components of these tree silages were correlated. Nine castrated lambs, without defined race, with initial average body weight of $30.7 \mathrm{Kg}$ were used, distributed in tree treatments and two
\end{abstract}

\footnotetext{
Parte da tese de Mestrado em Ciência Animal do primeiro autor.

2 Aluno de Pós-graduação em Ciência Animal, área de Produção Animal/UEL - DZOT

3 Professor do Departamento de Zootecnia da UEL. Londrina-PR. E-mail: leandro@uel.br.

${ }^{4}$ Professora do Departamento de Zootecnia (UNESP), Jaboticabal/SP.

5 Aluno de graduação em Zootecnia/PIBIC/CNPq/UEL - DZOT

* Autor para correspondência
} 
periods. The animals were placed in metabolic cages and the sorghum silage without additive provided higher intake of dry matter (DM), organic matter (OM), acid detergent fiber (ADF), neutral detergent fiber (NDF), total carbohydrates (TC) and hemicellulose (HEM). The apparent digestibility coefficient of the nutritive components did not differ when evaluated by the total feces collection. However, when using the LDA as marker there was significant difference to ADF, where the sorghum silage without additive was higher then sorghum silage with Lacto Silo. The sorghum silage with corn meal was similar to other two silages. There was significant correlation only to TC and HEM, between the two methodologies used to estimate.digestibility.

Key words: Correlation, corn meal, marker, inoculants, lignin

\section{Introdução}

As forrageiras tropicais apresentam estacionalidade de produção, ocorrendo sobra de alimento no verão e falta no inverno. A necessidade de intensificação da produção animal no Brasil obriga o produtor a fornecer alimentos de qualidade durante todo o ano. Sendo assim, o uso de forragens conservadas se torna uma ferramenta de importância na pecuária moderna.

As principais características nas forragens que determinam a extensão e o padrão da fermentação no silo são: o teor de matéria seca, quantidade de carboidratos solúveis, poder tampão e os microrganismos presentes na forragem durante o processo de ensilagem (WILKINSON, 1998; RODRIGUES et al., 2002).

Nem sempre se consegue, no momento da ensilagem, as condições ideais para uma boa confecção da silagem. $\mathrm{O}$ uso de aditivos parece ser uma alternativa interessante ao produtor visando corrigir os fatores que podem comprometer a qualidade da silagem produzida. Os principais objetivos do uso de aditivos são: melhorar a qualidade da fermentação no silo, reduzir perdas de nutrientes, melhorar a estabilidade da silagem depois de aberto o silo, aumentar o consumo e melhorar a performance do animal (WILKINSON, 1998; VILELA, 1998).

De modo geral, a qualidade de qualquer alimento é dada pelo seu valor nutritivo, representado pela sua composição química, pela digestibilidade dos seus constituintes, pelo consumo voluntário e pelo desempenho animal (VAN SOEST, 1994).

A determinação da digestibilidade é reconhecidamente a primeira aproximação na obtenção das estimativas dos parâmetros do valor nutritivo dos alimentos. Porém, na pesquisa em nutrição de ruminantes em condições de pastejo a sua determinação apresenta sérias dificuldades (PIAGGIO et al. 1991). Entretanto, a determinação da digestibilidade in vivo por intermédio do método tradicional de coleta total de fezes requer controle rigoroso da ingestão e excreção, o que o torna trabalhoso e oneroso.

Isto levou à idealização de outros métodos nomeados de métodos indiretos dos indicadores ou dos marcadores (SILVA, 1990). Estes métodos apresentam certas vantagens sobre o método de coleta total de fezes, a exemplo da simplicidade e conveniência de utilização, e podem proporcionar uma série de informações, incluindo-se a quantidade ingerida de alimentos ou de nutrientes específicos, a taxa de passagem da digesta por todo o trato digestivo e a digestibilidade de todo alimento ou nutrientes específicos (OLIVEIRA; FONTES; SILVA, 1991).

Constituintes naturais da dieta que apresentam baixa digestibilidade têm sido utilizados como indicadores. Os indicadores internos apresentam a vantagem de já estarem presentes no alimento e, de modo geral, permanecem uniformemente distribuídos na digesta durante o processo de digestão e excreção (PIAGGIO et al., 1991).

A lignina é comumente utilizada como um destes indicadores internos, em estudos de fluxo da digesta em ruminantes. Entretanto, os resultados obtidos com a utilização deste indicador têm se mostrados controversos. Piaggio et al. (1991) e Lançanova (1999) concluíram que a lignina em detergente ácido (LDA) foi efeciente na estimativa da digestibilidade 
dos nutrientes, em função de sua adequada recuperação. Entretanto, Cochran et al. (1986) concluíram que a LDA subestimou as digestibilidades. Muntifering (1982) obteve, no mesmo estudo, recuperações da LDA de 100,7 e 53,3\% para feno de copas de capim Kenhy e milho com sabugo, respectivamente.

Este trabalho teve como objetivos avaliar o consumo voluntário da silagem de sorgo (SS), da silagem de sorgo aditivada com fubá (SS + Fubá) e da silagem de sorgo aditivada com Lacto Silo (SS + Lac), estimar a digestibilidade aparente in vivo e pelo uso da lignina em detergente ácido como indicador, e correlacionar os valores das digestibilidades aparentes de alguns componentes nutritivos destas três silagens.

\section{Material e Métodos}

O ensaio de digestibilidade foi realizado nas instalações de metabolismos animal do Departamento de Zootecnia da Universidade Estadual de Londrina. Foram utilizados nove ovinos machos, castrados, sem raça definida, pesando em média $30,7 \mathrm{Kg}$, distribuídos ao acaso em três tratamentos e em dois períodos, tomando-se o cuidado para que os animais que recebessem determinado tratamento no primeiro período não recebessem o mesmo tratamento no segundo período.

Os animais foram alojados em gaiolas metabólicas apropriadas para coleta total de fezes e de urina, dotadas de cochos individuais para alimento. sal mineral e bebedouro.

Para confecção das silagens foi usado a rebrota do sorgo (Sorghum bicolor L. Moench) forrageiro (cultivar AG 2002), cortado em estádio pastoso dos grãos e ensilado em tubos de concreto com dimensões de 1 x $0,60 \mathrm{~m}$. A compactação foi feita através de pisoteio com indivíduos pesando em média $70 \mathrm{Kg}$.

Neste estudo foram utilizadas silagens de sorgo, silagens de sorgo aditivada com $5 \%$ de fubá de milho, na base matéria natural, e silagens de sorgo aditivada com Lacto Silo enzimático (Lactobacillus curvatus, L. acilophilus, L. plantarum, Predicoccus acidelactici, Lactobacillus sp.
Os aditivos foram misturados ao sorgo picado logo após a colheita e ensilados de tal forma que a massa ficasse o menor tempo possível em exposição ao ar e abertos após um mês de fermentação.

Os animais, após everminação e pesagens, foram sorteados conforme tratamentos e alojados em gaiolas metabólicos, submetidos a dez dias de adaptação, cinco dias para coleta de fezes e de sobras. Os mesmos foram pesados nos inícios e nos finais dos dois períodos para ajustar a ingestão e quantificar o consumo voluntário de matéria seca (CMS). O fornecimento de ração, feito em duas refeições às $8 \mathrm{~h}$ e $18 \mathrm{~h}$, foi de tal forma que houvesse sobra de $10 \%$ da matéria seca (MS) fornecida.

As rações, sobras e fezes foram amostradas diariamente, identificadas e armazenadas em congelador para posteriormente formar uma amostra composta para análises em laboratório. As amostras das fezes, de cada animal, consistiram de $20 \%$ do total excretado e ao final de cada período experimental as amostras de cada animal foram reunidas de tal forma que se obtivesse uma amostra composta por animal e por tratamento. As determinações de MS, matéria orgânica (MO), proteína bruta $(\mathrm{PB})$, fibra em detergente neutro (FDN) e fibra em detergente ácido (FDA) foram realizadas segundo metodologia descrita pelo Association of Official Analytical Chemists (1990). As determinações dos teores de hemicelulose foram feitas subtraindo os valores de FDA dos valores de FDN.

A metodologia utilizada para determinação dos teores de lignina foi descrita por Goering e Van Soest (1970) em ácido sulfúrico 72\%. Para determinações dos coeficientes de digestibilidade dos componentes nutritivos, pelo método de coleta total de fezes foi utilizado o sistema de equações citado por Coelho da Silva e Leão (1979). Para estimar a matéria seca fecal com lignina como indicador foram utilizadas as equações propostas por Valadares Filho et al. (1985).

Os resultados obtidos foram submetidos à análise de variância e as diferenças entre médias comparadas pelo teste de Tukey a 5\% de significância, utilizando-se o pacote estatístico SAS INSTITUTE (1997). No modelo matemático além do efeito de tratamento, considerou-se o efeito de blocos (períodos). 


\section{Resultados e Discussão}

Os teores médios de MS, MO, PB, FDA, FDN, carboidratos totais (CT), hemicelulose (HEM) e da lignina em detergente ácido (LDA) das silagens estudadas estão apresentadas na Tabela 1.
Os valores da composição bromatológica da silagem de sorgo (SS) foram muito próximos aos divulgados por Neumann et al., 2002; Martins et al., 2003a; Mizubuti et al., 2002; Souza et al., 2003, obtidos em trabalhos conduzidos com silagens de sorgo AG 2002.

Tabela 1. Teores médios de matéria seca (MS, matéria orgânica (MO), proteína bruta (PB), fibra em detergente ácido(FDA), fibra em detergente neutro (FDN), carboidratos otais (CT), hemicelulose (HEM) e lignina (LDA) das diferentes silagens de sorgo

\begin{tabular}{|c|c|c|c|c|c|c|c|c|}
\hline \multirow[t]{2}{*}{ Silagem } & \multicolumn{8}{|c|}{ Composição (\%) } \\
\hline & MS & $\mathrm{MO}$ & PB & FDA & FDN & $\mathrm{CT}$ & HEM & LDA \\
\hline $\mathrm{SS}^{1}$ & 24,17 & 20,79 & 6,18 & 44,51 & 73,89 & 78,00 & 29,38 & 4,90 \\
\hline $\mathrm{SS}+$ Fubá $^{2}$ & 25,17 & 21,87 & 6,18 & 37,38 & 63,21 & 78,47 & 25,84 & 4,62 \\
\hline $\mathrm{SS}+\mathrm{Lac}^{3}$ & 24,34 & 21,27 & 5,93 & 45,63 & 71,42 & 80,41 & 25,79 & 5,64 \\
\hline
\end{tabular}

1 - Silagem de sorgo; 2 - Silagem de sorgo + fubá; 3 - Silagem de sorgo + Lacto Silo

Na Tabela 2 podem ser observados os valores de consumo voluntário, obtidos com os ovinos, referentes às três silagens. A SS proporcionou maiores consumos dos componentes nutritivos avaliados do que quando os animais foram alimentados com a SS + Lac, com exceção do consumo de PB. A SS + Fubá apresentou valores intermediários às duas outras silagens, onde os consumos de MS, MO, CT e HEM foram semelhantes às duas outras silagens. Os consumos de FDA e FDN foram menores $(\mathrm{P}<0,05)$ em relação à $\mathrm{SS}$, e semelhantes à $\mathrm{SS}+$ Lac. Já o consumo de $\mathrm{PB}$ não diferiu $(\mathrm{P}>0,05)$ das outras silagens estudadas. Os valores de consumo encontrados para SS estão próximos aos encontrados por outros autores (SOUZA et al., 2003, MARTINS et al., 2003a; MARTINS et al., 2003b). Esperava-se que, com a adição dos aditivos, fubá de milho ou Lato silo, resultasse em melhores condições fermentativas do sorgo de rebrota. Nestas condições, em termos de consumo, pode-se afirmar que o sorgo em rebrota não necessita de ser aditivado para se obter silagens que propicie maiores ingestões.

Tabela 2. Consumo médio diário de matéria seca $(\mathrm{MS})$, matéria orgânica $(\mathrm{MO})$, proteína bruta $(\mathrm{PB})$ fibra em detergente ácido (FDA), fibra em detergente neutro (FDN), carboidratos totais (CT), hemicelulose (HEM) das diferentes silagens de sorgo em $\mathrm{g} / \mathrm{kg} \mathrm{PV}^{0,75} / \mathrm{dia}$

\begin{tabular}{llllllll}
\hline Silagem & \multicolumn{7}{c}{ Consumo em g/ kgPV 0,75} \\
\cline { 2 - 7 } & MS & MO & PB & FDA & FDN & CT & HEM \\
\hline SS $^{1}$ & $53,10^{\mathrm{a}}$ & $45,60^{\mathrm{a}}$ & $3,28^{\mathrm{a}}$ & $23,33^{\mathrm{a}}$ & $39,03^{\mathrm{a}}$ & $41,26^{\mathrm{a}}$ & $15,70^{\mathrm{a}}$ \\
$\mathrm{SS}+$ Fubá $^{2}$ & $45,65^{\mathrm{ab}}$ & $39,65^{\mathrm{ab}}$ & $2,96^{\mathrm{a}}$ & $15,80^{\mathrm{b}}$ & $27,56^{\mathrm{b}}$ & $35,60^{\mathrm{ab}}$ & $12,09^{\mathrm{ab}}$ \\
$\mathrm{SS}+\mathrm{Lac}^{3}$ & $36,06^{\mathrm{b}}$ & $31,54^{\mathrm{b}}$ & $2,28^{\mathrm{a}}$ & $15,47^{\mathrm{b}}$ & $24,69^{\mathrm{b}}$ & $28,81^{\mathrm{b}}$ & $8,89^{\mathrm{b}}$ \\
$\mathrm{CV}(\%)$ & 20,54 & 20,84 & 25,63 & 21,92 & 22,91 & 20,89 & 28,74 \\
\hline
\end{tabular}

1 - Silagem de sorgo; 2 - Silagem de sorgo + fubá; 3 - Silagem de sorgo + Lacto Silo

Médias seguidas de letras diferentes na mesma coluna diferem $(\mathrm{P}<0,05)$ pelo teste de Tukey. 
Na Tabela 3 são apresentados os valores dos coeficientes de digestibilidade dos componentes nutritivos das silagens estudadas.
Apesar dos valores dos coeficientes de digestibilidade de SS + fubá e de SS + Lac se mostrarem numericamente menores que $\mathrm{SS}$, tais valores não diferiram $(\mathrm{P}>0,05)$.

Tabela 3. Coeficientes de digestibilidade aparente da matéria seca (MS), matéria orgânica (MO) proteína bruta (PB), fibra em detergente ácido (FDA), fibra em detergente neutro (FDN) carboidratos totais (CT) e hemicelulose (HEM) das diferentes silagens de sorgo pela coleta total de fezes

\begin{tabular}{lccccccc}
\hline Silagem & \multicolumn{7}{c}{ Coeficientes de Digestibilidade (\%) } \\
\cline { 2 - 7 } & MS & MO & PB & FDA & FDN & CT & HEM \\
\hline SS $^{1}$ & 52,71 & 31,13 & 51,89 & 56,93 & 52,46 & 53,18 & 64,38 \\
SS + Fubán & 51,20 & 30,54 & 48,80 & 53,70 & 51,08 & 51,95 & 61,10 \\
SS + Lac $^{3}$ & 44,95 & 26,76 & 38,73 & 48,78 & 44,98 & 46,36 & 60,84 \\
CV (\%) & 30,28 & 70,05 & 28,39 & 25,35 & 31,84 & 31,30 & 25,79
\end{tabular}

1 - Silagem de sorgo; 2 - Silagem de sorgo + fubá; 3 - Silagem de sorgo + Lacto Silo

Médias não diferem $(\mathrm{P}>0,05)$ pelo teste de Tukey.

Martins et al. (2002a) e Martins et al. (2003b), trabalhando com híbrido AG 2002, encontraram valores para os coeficientes de digestibilidade aparente para MS, PB, FDA e FDN de 49,83\%, $32,66 \%, 39,65 \%$ e $39,65 \%$, respectivamente, com ovinos. Os resultados encontrados neste estudo foram superiores aos divulgados por Mizubuti et al. (2002), que, também trabalharam com AG 2002 em ovinos.
No entanto, os resultados encontrados no presente trabalho foram próximos aos divulgados para MS, PB e CT por Souza et al. (2003), estudando híbrido AG 2002 com ovinos.

$\mathrm{Na}$ Tabela 4 são apresentados os valores dos coeficientes de digestibilidade dos componentes nutritivos das diferentes silagens de sorgo tendo como indicador a LDA.

Tabela 4. Coeficientes de digestibilidade aparente da matéria seca (MS), matéria orgânica (MO), proteína bruta (PB), fibra em detergente ácido (FDA), fibra em detergente neutro (FDN), carboidratos totais (CT) e da hemicelulose (HEM) das diferentes silagens de sorgo tendo como indicador a lignina em detergente ácido (LDA)

\begin{tabular}{lccccccc}
\hline Silagem & \multicolumn{7}{c}{ Coeficientes de Digestibilidade (\%) } \\
\cline { 2 - 7 } & MS & MO & PB & FDA & FDN & CT & HEM \\
\hline SS $^{1}$ & $57,72^{\mathrm{a}}$ & $49,51^{\mathrm{a}}$ & $28,72^{\mathrm{a}}$ & $49,87^{\mathrm{a}}$ & $55,97^{\mathrm{a}}$ & $50,30^{\mathrm{a}}$ & $64,98^{\mathrm{a}}$ \\
$\mathrm{SS}+$ Fubá $^{2}$ & $55,44^{\mathrm{a}}$ & $47,64^{\mathrm{a}}$ & $25,03^{\mathrm{a}}$ & $44,50^{\mathrm{ab}}$ & $49,98^{\mathrm{a}}$ & $48,44^{\mathrm{a}}$ & $58,09^{\mathrm{a}}$ \\
$\mathrm{SS}+$ Lac $^{3}$ & $52,89^{\mathrm{a}}$ & $40,42^{\mathrm{a}}$ & $19,54^{\mathrm{a}}$ & $33,35^{\mathrm{b}}$ & $43,76^{\mathrm{a}}$ & $41,86^{\mathrm{a}}$ & $56,77^{\mathrm{a}}$ \\
$\mathrm{CV}(\%)$ & 19,75 & 22,42 & 43,24 & 21,18 & 17,61 & 22,80 & 19,58
\end{tabular}

1 - Silagem de sorgo; 2 - Silagem de sorgo + fubá; 3 - Silagem de sorgo + Lacto Silo

Médias seguidas de letras diferentes na mesma coluna diferem $(\mathrm{P}<0,05)$ pelo teste de Tukey. 
Na avaliação da digestibilidade aparente pela LDA, o único coeficiente que apresentou variação entre os três tratamentos foi a FDA, onde a silagem de sorgo sem aditivo foi superior, com $49,87 \%$ de digestibilidade. A SS + Lac foi a que apresentou menor $(\mathrm{P}<0,05)$ coeficiente de digestibilidade aparente para FDA. A SS + Fubá apresentou valores intermediários às outras duas silagens, não diferindo das mesmas.
A Tabela 5 mostra a correlação entre os componentes nutritivos estudados nos diferentes métodos de estimação do coeficiente de digestibilidade aparente. Observa-se que houve correlação significativa apenas para digestibilidade aparente dos carboidratos totais e digestibilidade aparente da celulose.

Tabela 5. Coeficiente de correlação linear ( $\mathrm{r}$ ) entre as metodologias, com respectivas probabilidades (P)

\begin{tabular}{lcc}
\hline Variáveis & $\mathrm{R}$ & $\mathrm{P}$ \\
\hline DMS & 0,20047 & 0,4251 \\
DMO & 0,36790 & 0,1331 \\
DPB & 0,20207 & 0,4213 \\
DFDA & 0,38875 & 0,1109 \\
DFDN & 0,38282 & 0,1169 \\
DCT & 0,64112 & 0,0041 \\
DHEM & 0,74626 & 0,0004
\end{tabular}

DMS, DMO, DPB, DFDA, DFDN, DCT,E DHEM - Coeficientes de digestibilidades aparentes da matéria seca, matéria orgânica, proteína bruta, fibra em detergente ácido, fibra em detergente neutro, carboidratos totais e da hemicelulose, respectivamente.

Piaggio et al. (1991) avaliaram três indicadores (cinza insolúvel em ácido, fibra em detergente ácido e LDA, com feno de alfafa em ovinos) concluíram que a LDA apresentou um comportamento aceitável como indicador interno de digestibilidade. Lançanova (1999) estudando a digestibilidade in vivo e pela LDA de uma ração completa, composta por $44,3 \%$ de feno de gramínea, $55 \%$ de concentrado e $0,7 \%$ de mistura mineral fornecida a zebuínos e taurinos, concluiu que a LDA foi eficiente na estimativa da digestibilidade dos nutrientes, em função de sua adequada recuperação.

Cochran et al. (1986), comparando as digestibilidades aparentes obtidas por quatro indicadores internos com digestibilidades aparente in vitro de feno de alfafa peletizado, ponteiras de gramínea, gramíneas frescas e $0,9 \mathrm{Kg}$ de farelo de soja e feno de gramíneas, em bovinos, concluíram que a LDA subestimou as digestibilidades de todas as dietas. Muntifering (1982) encontrou uma recuperação fecal da lignina em detergente ácido de $100,7 \%$ para cordeiros consumindo feno de copas de capim kenhy. Contudo, neste mesmo trabalho, os autores encontraram uma recuperação do mesmo indicador de 53,3\% para milho com sabugo.

\section{Conclusões}

A utilização da lignina não se mostrou eficiente como indicador para estimativas de coeficientes de digestibilidade aparente para os diferentes componentes nutritivos estudados. Mais estudos são 
necessários para validar a utilização da lignina em detergente ácido como indicador.

Com base nos dados do presente experimento não se pode recomendar o uso de qualquer dos aditivos estudados, pois estes não apresentaram melhorias no consumo e na digestibilidade da silagem de sorgo.

\section{Referências}

ASSOCIATION OF OFFICIAL ANALYTICAL CHEMISTS - AOAC. Official methods of analysis. Arlington: AOAC, 1990.

COCHRAN, R. C; ADAMS, D. C.; WALLACE, J. D.; GALYEAN, M. L. Predicting digestibility oa different diets with internal markers: evaluation of four potential markers. Journal of Animal Science, Champaign, v.63, n.5, p.1476$1483,1986$.

COELHO DA SILVA, J. F.; LEÃO, M. I. Fundamentos de nutrição de ruminantes. Piracicaba: Livroceres, 1979.

GOERINNG, H. K.; VAN SOEST, P. J. Forage fiber analyses: apparatus, reagents, procedures and some applications. Washington: Agricultural Research Service, 1970. p.379.

LANÇANOVA, J.A.C. Estimativas do aproveitamento de nutrients por meio da digestão "in vitro" e por indicador natural em taurinos e zebuínos. 1999. Tese (Doutorado em Zootecnia) - Universidade Estadual Paulista, Jaboticabal.

MARTINS, R. G. R.; GONÇALVES, L. C; RODRIGUES, J. A. S; RODRIGUEZ, N. M; BORGES, I; BORGES, A. L. C. C. Consumo e digestibilidade aparente da matéria seca, da proteína bruta e da energia de silagens de quatro genótipos de sorgo (Sorghum bicolor, L. Moench) por ovinos. Arquivo Brasileiro Médicina Veterinária e Zootecnia, Belo Horizonte, v.55, n.3, p.341-345, 2003 a.

MARTINS, R. G. R.; GONÇALVES, L. C.; RODRIGUES, J. A. S.; RODRIGUEZ, N. M; BORGES, I; BORGES, A. L. C. C . Consumo e digestibilidade aparente das frações fibrosas de silagens de quatro genótipos de sorgo (Sorghum bicolor, L. Moench) por ovinos. Arquivo Brasileiro Médicina Veterinária e Zootecnia. v.55, n.3, p.346-349, 2003b.

MIZUBUTI, I.Y.; RIBEIRO, E.L.A.; ROCHA, M.A.; SILVA, L. D. F.; PINTO, A. P.; FERNANDES, W. C.; ROLIM, M. A.. Consumo e digestibilidade aparente das silagens de milho (Zae mays L.), sorgo (Sorghum bicolor, $(L)$. Moench) e girassol (Helianthus annuus L.). Revista Brasileira de Zootecnia, Viçosa, v.31, n.1, p.267-272, 2002.
MUNTIFERING, R. B. Evaluation of various lignin assays for determining ruminal digestion of roughages by lambs. Journal of Animal Science, Champaign, v.55, n.2, p.433438, 1982.

NEUMANN, M.; RESTLE, J.; ALVES FILHO, D. C.BERNARDES, R. A. C.; ARBOITE, M.Z.; CERDOTES, L.; PEIXOTO, L. A.. O. Avaliação de diferentes híbridos de sorgo (Sorghum bicolor, L. Moench) quanto aos componentes da planta e silagens produzidas. Revista Brasileira de Zootecnia, Viçosa, v.31, n.1, p.302-312, 2002.

OLIVEIRA, R. F. M.; FONTES, C. A. A; SILVA, J. F. C. Estudo da recuperação fecal de $\mathrm{CR}_{2} \mathrm{O}_{3}$ e dos indicadores internos CIA, CIDA e lignina em períodos de coleta de dois a sete dias, em bovinos. Revista Brasileira de Zootecnia, Viçosa, v.20, n.5, p.522-531, 1991.

PIAGGIO, P. H. M.; SENATORE, A. L.; ANDRADE, S. J.T. et al. Efeitos da adição de inoculantes microbianos sobre a composição bromatológica e perfil fermentativo da silagem de sorgo produzida em silos experimentais. Revista Brasileira de Zootecnia, Viçosa, v.20, n.3, p.306-312, 1991.

RODRIGUES, P. H. M.; SENATORE, A. L.; ANDRADE, S. J. T.;RUZANTE, J. M.; LUCCI, C. S.; LIMA, F. R. Efeitos da adição de inoculantes microbianos sobre a composição bromatológica e perfil fermentativo da silagem de sorgo produzida em silos experimentais. Revista Brasileira de Zootecnia, Viçosa, v.31, n.6, p.2373-2379, 2002.

SAS INSTITUTE. SAS/STAT: Cary: User's guide, 1997. v.2. 846p.

SILVA, D. J. Análise de alimentos: métodos químicos e biológicos. 2.ed. Viçosa: UFV, 1990.

SOUZA, V. G.; PEREIRA, O. G.; MORAES, S. A.; GARCIA, R.; VALADARES FILHO, S. C.; ZAGO, C. P.; FREITAS, E. V. V. Valor nutritivo de silagens de sorgo. Revista Brasileira de Zootecnia, Viçosa, v.32, n.3, p.753-759, 2003.

VALADARES FILHO, S. C.; COELHO, J. F. S.; LEÃO, M. I.; GONÇALVES, C. A..C.; GARCIA, J. A. Óxido crômico e lignina na determinação dos fluxos de matéria seca abomasal, ileal e fecal em bovinos e bubalinos. Revista da Sociedade Brasileira de Zootecnia, Viçosa, v.14, n.5, p.565-574, 1985.

VAN SOEST, P.J. Nutritional ecology of the ruminants. 2.ed. Ithaca: Cornell University, 1994.

VILELA, D. Aditivos para silagem de plantas de clima tropical. In: WECHSLER, F. S.; Aditivos na produção de ruminantes e não ruminantes. Botucatu: UNESP, 1998. p.73-108.

WILKINSON, J.M. Additives for ensiled temperate forage crops. In: WECHSLER, F. S.; Aditivos na produção de ruminantes e não ruminantes. Botucatu: UNESP, 1998. p.73-108. 